\title{
sciendo
}

\section{The role of risk management in increasing business performance}

\author{
Hasan MAKKAWI \\ Bucharest University of Economic Studies, Bucharest, Romania \\ hasan.makkawi93@gmail.com
}

\begin{abstract}
The study aims at clarifying the role of risk management in improving business performance. In this study a literature review has been employed in order to understand the subject matters in managing business risks to increase company performance. The literature reviewed shows that risk management does contribute to the improvement of the business performance, measured as increase of company profits, decrease of business costs and, in turns, increase in economic proficiency. Therefore, the risk management impacts, in a positive way, the quality of a business that is embodied in improving the financial status of the company, increasing the profits, as well as decreasing the costs. Some recommendations are made for decision makers in the insurance business sector, who are required to be fully aware of the influence that risk management has on helping their business flourish. This is advisable through decreasing the cost of production, increasing profits, and improving financial business situation in their companies. Also, company decision makers are required to work continuously to develop risk management to increase profits, reduce costs, and improve the financial situation, and thus improve business performance.
\end{abstract}

Keywords: Improving risk management, Business performance, Insurance industries, Risk management steps, Increasing business profits, Decreasing business cost, Business financial situation.

\section{Introduction}

Nowadays, risk management is considered highly important in improving the economy on a local as well as an international level. Throughout the quick change of variables in the business field, risk management has proved to be one of the most demanded variables companies invest in to ensure their presence among the other competitors on the floor. Due to globalization and free market, risk management is used in both developing and developed countries to make sure that a business survives regarding any challenges. For example, confronting the obstacles of the current COVID-19 pandemic and ensuring a constant profit would not have been possible without good strategies and knowledge of risk management.

Decision makers in the insurance business domain are required to be fully aware of the influence risk management has on helping their business flourish through decreasing the cost of production, increasing profits, and remaining as a competitor, no matter what challenges and unexpected problems they might face. This study explores risk management in a scientific way where the researcher suggests a few questions regarding the role risk management plays in improving business performance. In order to find answers to this major question, the researcher has introduced the following questions: (1) Does risk management play a role in increasing business profits? (2) Does risk management play a role in decreasing business cost? (3) Does risk management play a role in improving the business financial situation?

This study tries to clarify the role of risk management in improving business performance in terms of the financial situation of a company, costs, as well as profits amid the continuous increased risk. Improving the previous terms shall make a business more efficient, and their performance better and continuous as well. 


\section{Literature review}

Even though there is no specific definition of a risk, it can be referred to as anything of which we are uncertain (Rejda, et al., 2014). Also, (Keshk et al., 2018) refer to risks as any uncertain events that might affect, whether positively or negatively, the objectives of a project.

However, COSO has defined risk management as a process that is carried out by the Board of Directors, administration along with other employees. This process is applied to develop a strategy and to identify potential events that may affect the business in order to make them within the scope of the acceptable risks, what will ensure the achievement of the business objectives (Shad et al., 2019). As for the definition of risk management, they are defined as: "Pre-decisionmaking process that aims at reducing future risks by identifying, analyzing, studying and planning the anticipated risks." (Shad et al., 2019). It is to be emphasized here that insurance is considered as a way of dealing with the unexpected effects of risk on a company's economy.

Understanding risks and risk management is important for insurance companies (SMEs) since their work becomes more effective when they can reduce risk and adapt to it. Thus, risk management has become a modern process that allows the company to control prices, compete in the market, gain higher profits and improve business performance (Jia et al., 2020). In this context, business performance includes achieving tasks that help to fulfil the business objectives. It also pays attention to the performance of employees and managers and how they work together to minimize any risks in order to reduce costs, increase profits and improve the financial situation, as an attempt to improve business performance (Borghesi et al., 2013). It is worth mentioning that all those terms are connected together and related to one another, that is why insurance companies need to understand the risks and be ready with their risk management strategies.

Insurance, as a process, changes and evolves everyday what results in some human mistakes and error due to the possible miscalculations of the source of risks as well as its size. However, the economic domain holds a lot of issues and troubles to which one can possibly either find solutions, minimize or totally avoid. But there are also those kinds of risks that are unexpected. That is why it is important to improve risk management in insurance field (Jia. et al., 2020). The importance of risk management in the insurance field is represented in minimizing the total risk compensation, identifying priorities of compensation, better understanding of the timing of risk, choosing the most suitable available methods of compensation in order to guarantee profits, and finally minimizing additional unit cost during production. Adopting risk tools and making use of risk managing strategies both contribute to minimizing risks, increasing profits, reducing costs. This, in turns, makes the financial situation of insurance companies much better and leads to an increase in the business performance (Eckles, 2014).

The (Shaheen et al., 2020) study aimed at clarifying the relationship between sustainable risk management and risk management of the institution in Palestinian insurance companies. The results showed that there is a positive relationship between risk management and the use of corporate risk management with an increased profitability, where profits increase with the use of improved risk management strategies. The study also shows that there are many risks that Palestinian insurance companies face and that directly affect the profit, such as the political instability and the unsuitable prices that does not correspond with the current economic situation. Therefore, there is a relationship between the application of risk management and profits, especially in the Palestinian insurance sector. Shaheen's et al study also relates to the current study in terms of the application of risk management in the Palestinian insurance market; however, this study is more comprehensive because it focusses on improving risk management, and its steps to 
increase profits, reduce costs, and improve the financial situation so that it increases business performance in the insurance industry.

Altuntas et al. (2019) investigated whether institutional risk management helps to achieve economies of scale and scope. A detailed survey of insurance companies (responsible for real estate) was used in order to measure the quality in risk management. The results showed that there is a positive effect of risk management on diversity, income and efficiency. The current study focuses not only on quality in risk management but also on business performance and improving risk management beside reducing costs as well as improving the financial situation of a business.

A study conducted by (Crovini et al. 2020) reviewed the main role of risk management (RM) in small and medium enterprises SMEs by identifying, analyzing and clarifying the most important international business and finding out why risk management is not making a progress.

Furthermore, similar to the current study, Crovini et al. study tackles the importance of technology in addressing risks. For instance, modern technology and digital media has proved themselves to be part of the solution during the situation of the current COVID-19 pandemic along with the accompanying risks. The current study focusses on the role of risk management in insurance companies in facing COVID-19 pandemic and improving business performance in such competitive atmosphere, so that they can survive and increase profits, decrease costs, and improve business financial situation.

(Jia et al., 2020) investigated the relationship between the "best practices" of risk management committee and the company's performance in an environment where the existence and formation of risk management committees are entirely voluntary. Data collected from 368 Australian companies showed that companies that have voluntarily adopted "best practices" in the risk management committee perform better than other companies. Risk management plays an important role in raising the company's performance. Unlike Bradbury's study that does not really focus on the insurance sector, the current study focuses on the necessity of having risk management committee in insurance companies so they can clarify, develop risk management, and adopt best practices to deal with risks in order to improve business performance in insurance industry.

A recent research conducted by (Shad et al. 2019) investigated the implementation of enterprise risk management by focusing on the additional value in business performance and its relation to sustainability that is integrated within the business strategy. Through a qualitative analysis it measures performance and its effect on risk management of businesses. The results of the study can be summarized in the fact that improving business performance is achievable through customizing prices in order to gain profit and to reduce the cost of capital. On one hand, this can be done through reducing risks. On the other hand, obtaining all the possible information that can clarify the risk through an exciting collaboration between insurance companies and stakeholders. The current study builds upon( Shad et al., 2019) research. However, it largely relates the increased profits and reduced costs to the additional value. Also, business performance tools are different in both studies.

(Deakins et al., 1997) showed that large-sized companies are exposed to many risks, including technology risks and therefore costs in these companies are higher. The study also indicates that there is a poor relationship between insurance brokers and insurance companies because of the product; there is a failure to meet the technology-related needs due to technology risks. It is therefore expected that there will be an inability to assess costs and its impact on profit. Dickens' et al study focuses on technology risks with samples from Scotland. It shows the existing trend of companies working remotely due to the Covid-19 pandemic. Thus, we can make benefit 
of this study by focusing on technology-related risks to achieve profits, reduce costs and improve the financial situation.

Wang et al. (2019) study indicated the risks that could reduce the profitability of insurance companies. 214 companies were analyzed between 2006-2018 in America. Factors that were the cause of risk from the beginning of the establishment of risk management are: legal and regulatory risks and the emergence of liquidity risks in 2006, market risks in 2007, business risks in 2010, operational risks in 2014. The result of this study was that operational risks are one of the most important risk factors that must be studied and paid attention to in risk management. Insurance companies must focus on operational risks and risks that affect performance and profitability.

As per (Etlin et al., 2020) the risk transfer is one of the risk management tools that increase profits, reduce costs and improve the financial situation of insurance companies. When it focuses on risk transfer, that will mitigate risks, manage capital requirements in the insurance network environment decrease costs, thus increase profits. There are similarities between this study and the current one, but here the focus has been on transferring risks through insurance networks that in turn reduce costs, increase profits, and improve the financial situation.

\section{Methodology}

The current study uses a theoretical presentation of previous literatures that shows improvement of business performance through the role of risk management in insurance sector. The researcher has followed a qualitative method in reviewing the previous literature and have collected data and information from books, journal articles online research and annual reports.

The technique utilized by the researcher in this study were based on a series of research questions designed to explore the role risk management plays in improving business performance.

Based on available literature, this study conducted in a manner that utilizes descriptive research to shed light on the role of risk management in improving business performance in insurance sector.

An extensive search using the research keywords was done on online date basis, and the targeted publications were selected based on the keywords they have in common with the current study.

Seventeen research papers related to the topic under study were reviewed. Seven papers were included in the literature view and referred to in the study. Only papers that discussed the role of risk Management in increasing business performance or those that dealt with the same topic in the insurance context were selected.

Data was analyzed and collected from the consulted papers to match the aim of the study, which is to educate decision-makers in the insurance sector about the role that risk management plays in increasing business performance as well as profit.

\section{Results and discussions}

According to ISO 31000, the application of management steps that include communication and advice, setting the context, identifying, analyzing, assessing, and handling risks, along with monitoring and auditing help insurance companies improve their financial situation. (Selyaseelan, 2018).

Insurance companies that pay attention to the steps of risk management, especially the identification, evaluation, and control of risks are more likely to improve their financial situation. This is also a result this research has in common with (Crovini et al., 2020). 
The risk management department must focus on providing information that clarifies the risks. It needs to cooperate with the company's departments in order to improve prices, that, in turn, increase profits and reduce costs (Shad el at., 2019).

Risk management departments of insurance companies that focus on operational risks increase their profits and reduce the costs. This leads to improvement in the financial situation and positively affects the business performance.

Insurance companies that focus on technology-related strategies of risk management and

try to keep up with and adapt to the technology can increase profits and reduce costs. As observed in the context of the current Covid-19 pandemic.

The study finds that there are many tools to control and manage risks, including risk transfer to insurance networks which is the best way to reduce costs, increase profits, and improve the financial situation, which is also one of the findings of (Rejda et al., 2014) research paper.

In addition, risk control is not only about resolving them, but also about avoiding, preventing, and reducing them before they occur; which actually reduces costs.

Risk financing could be achieved through keeping part of the risks, non-insurance transfers, insurance transfers. The latter is the most used in insurance companies and is often called the risk transfer process. This process helps to increase the profit of all the sides that contribute to it.

Risk management and its role in increasing profits and reduce costs has great significance and impact on all economic aspects and on the insurance sector, in particular.

\section{Conclusion}

After exploring the previous literature that tackled risk management and its role in increasing business performance in insurance companies, it was noticed that there are insufficient interest and research in this field. So, this study tries to raise awareness of the role of risk management in increasing profits, reducing costs, and improving the financial situation of insurance companies in order to improve the business performance as a whole.

Decision-makers in the insurance sector should be aware of the fact that focusing on risk management and applying its steps will increase their business performance, profits, reduce costs and improve their financial situation.

In addition, managers responsible for utilizing as well as developing risk management strategies should consider diversifying profit resources and competencies. This contributes to increasing profits, reducing costs, and improving the financial situation.

Furthermore, there should be an active collaboration between all departments, depending on the risks they hold, to ensure the prices are properly estimated. This will, in turn, decrease costs, multiply profits, and improve the financial situation of the company.

As pointed out in the literature review, there are many forms of risks and factors that are causing risks. It is to be noted, to decision-makers in the insurance sector, that paying attention mainly to operational risks in insurance companies reduces potential costs and losses and increases the profit, given their importance to the overall economy.

During the current situation of the Covid-19 pandemic, there are risks that face insurance companies and insured companies. However, those companies are the most in need to continue working, preserving funds, and apply risk management steps so that they can face the risks resulting from the lockdown, which is something decision-makers should pay attention to. This should ensure increased profit, decreased costs, better financial as well as improved performance. 
Risk transfer is also a strategy that needs to be more celebrated by decision-makers. Implementing this strategy leads to reducing costs and increasing profits; thus, improving the financial situation along with business performance.

In conclusion, decision-makers in the insurance business sector are required to be fully aware of the influence risk management has on helping their business flourish through decreasing the cost of production, increasing profits, and improving the financial business situation of their companies. Also, they have to work continuously to develop various effective risk management strategies so as to guarantee a highly-performing business.

\section{References}

Altuntas, M., Berry-Stolzle, T.R., \& Cummins, J.D. (2019). Enterprise risk management and economies of scale and scope: evidence from the German insurance industry, Journal Annals of Operations Research.

Borghesi, A., \& Gaudenzi, B. (2013). Risk management how to assess transfer and communicate critical risks, springer-verlag.

Crovini, C., Ossola, G., \& Britemaier, B. (2020). How to reconsider risk management in SMEs? An Advanced, Reasoned and Organised Literature Review, European Management.

Deakins, D., \& Paddison, A. (1997). Issues in a regional comparison of risk management, insurance and high technology small firms, New Techology-Based Firms, 7-17.

Eckles, D., Hoyt, R., \& Miller, S. (2014). The impact of enterprise risk management on the marginal cost of reducing risk. Evidence from the insurance industry, Journal of Banking \& Finance, 43, 247-261.

Etlin, N., Farkas, W., Kull, A. \& Smirnow, A. (2020). the risk transfer is one of the risk management tools that increase profits, Insurance mathematices and Economics, 1-30.

Jia, J., \& Bradbury, M. (2020). Complying with best practice risk management committee guidance and performance, Journal of Contemporary Accounting \& Economics, 16, 3.

Keshk, A., Maarouf, I., \& Annany, Y. (2018). Special studies in management of construction project risks, risk concept, plan building, risk quantitative and qualitative analysis, risk response strategies, Sciencepirect, 57, 4, 3179-3187.

Rejda, G.E., \& McNamara, M.J. (2014). Principles of risk management and insurance, Library of Congress Cataloging-in-Publication.

Selvaseelan, J. (2018). Communication Development and Introduction of the Risk-Sentience Auxiliary Framework (RSAF) as an Enabler to the ISO 31000 and ISO 31010 for HighRisk Environments, Administrative Sciences - Open Access Journal.

Shad, M., Lai, F., Fatt, C., Klemesij, J., \& Bokari, A. (2019). Integrating sustainability reporting into enterprise risk management and its relationship with business performance: A conceptual framework, Journal of Cleaner Production, 208, 415-425.

Shaheen, R., Aga, M., Rjoub, H., \& Abualrub, A. (2020). Investigation of the Pillars of Sustainability Risk Management as an Extension of Enterprise Risk Management on Palestinian Insurance Firms' Profitability, Sustainabilitys, 12, 11.

Wang, Y., Lic, B., Li, G., Zhu, X., \& Lia, J. (2019). Identify risk factors and analyze evolution from the text Risk disclosure for the insurance industry. The $7^{\text {th }}$ International Conference on Information Technology and Quantitative Management. Institutes of Science and Development, Chinese Academy of Sciences. 